\title{
Cognitive style and Computer-Assisted Learning: problems and a possible solution ${ }^{1}$
}

\author{
John A. Clarke \\ School of Learning and Development, Kelvin Grove Campus, Queensland University \\ of Technology, Locked Bag No 2, Red Hill, Brisbane, Australia 4059
}

\begin{abstract}
Although the notion of cognitive style has been around for some time, only in relatively recent times has there been a research interest in examining its effect on the performance of Computer-Assisted Learning (CAL) users. There are a number of practical difficulties associated with catering for different cognitive styles of CAL users. This paper identifies not only a style which influences CAL-user performance and overcomes many of the difficulties, but also a possible suitable measure of that style. Data on the reliability of this measure is reported, along with preliminary work on its use to cater for CAL users with different cognitive styles. Future work will focus on the development of the package and the predictive validity of the style measure.
\end{abstract}

\section{Cognitive styles and Computer-Assisted Learning (CAL)}

Cognitive style has been variously defined (e.g. Kogan, 1971; Messick, 1970, 1976, 1984) but essentially means the unique and preferred way in which individuals process information. Although the notion can be traced back to the beginning of the century (Coop and Sigel, 1971), it gained recognition in the 1950 s and 1960 s as a significant personal characteristic which increased the understanding of how people learn (e.g. Witkin et al, 1962). However, recognition of its importance in education generally (Kogan, 1971; Messick, 1970, 1976, 1984) and CAL specifically (James and James, 1990; Sharma, 1987; Sims, 1988) has been relatively recent.

Since any computer-assisted information system consists of three major components hardware, software and the user - it is important that the concept of cognitive style as a significant characteristic of the user be catered for in the production of a CAL program. 
Although there has been recognition of this for some time (Barker, 1982), there are still consistent calls for the development of programs which allow users to choose how they wish to learn (Chadwick and Watson, 1986; Duncan, 1985).

A plethora of cognitive styles has been identified and reported (e.g. Kogan, 1971; Joughin, 1989; Rowland and Stuessy, 1987) but often, the styles differ more in name than in nature. The vast majority of cognitive styles can be classified into either a preference for a reasonable degree of structure and guidance to be provided in the learning situation, or a preference for considerable freedom to choose the direction that learning should take. Essentially, this is preference for structured guided instruction versus unstructured discovery learning. As far as the delivery of CAL is concerned, the 'structured' end of the continuum is catered for by the traditional tutorial-type programs while the 'unstructured' end is served best by simulation/ game-type programs.

\section{Problems in catering for cognitive styles}

There are a number of practical difficulties associated with trying to cater for different cognitive styles:

\section{The vast number of styles}

As already noted, many styles have been identified, researched and reported but the vast majority can be coalesced into a continuum ranging from a heavy dependence on structure and guidance, to a strong preference for minimal structure and guidance.

\section{The measurement of styles}

Many measures of cognitive style have to be individually administered - such as the rod-and-frame test for field dependence-independence (Witkin et al, 1962) - and hence are not time- and cost-effective. Most of these individual measures are complemented by group pencil-and-paper tests, the Group Embedded Figures Test for field dependence-independence, for example (Witkin et al, 1971) but these still require considerable time to complete and analyse.

\section{Incorporating the measure of style into the CAL program}

Research investigating the relationship between cognitive style and CAL performance has invariably measured style independently of the user's involvement with the program and has used non-computer-based procedures (e.g. James and James, 1990; Rowland and Stuessy, 1987). This again is time-consuming, and feedback on the appropriate type of program for the user is delayed. Ideally, any measure of style should occur as an immediate prerequisite to involvement in the program. A computer-based measurement procedure would also streamline the process. 


\section{Preparing appropriate versions of the same program to cater for different styles.}

Most research focuses either on how CAL users with different styles cope with a particular CAL presentation (e.g. Clements and Gullo, 1984; Post, 1985) or on learners' comparative performance in CAL versus other non-computer-based modes of presenting material (e.g. Dahl, 1985; Wesley, 1984). There has been some research that has attempted to match style with an appropriate CAL presentation (e.g. Rowland and Stuessy; 1987).

\section{A possible solution}

To overcome these problems, what is required is the identification of a style which is meaningful in the context of learners interacting with $\mathrm{CAL}$ materials, which can be measured easily and reliably and which can be incorporated in the CAL presentation. Once this is achieved, the next step is to prepare an appropriate CAL package which can accommodate the different learning styles which have been identified.

The earlier discussion highlighted a style which not only subsumes many of the disparate styles in the literature but is also appropriate to CAL presentation. The style ranges on a continuum from a preference for a reasonable degree of structure and guidance to be provided in the learning situation, to a preference for considerable freedom to choose the direction that learning should take. Such a style has been identified by Pask and his co-workers (Pask, 1973, 1976; Pask and Scott, 1972). The learners at the two extremes of the continuum are referred to as 'serialists' and 'holists'. Serialists prefer to learn just the essential facts which should be well defined, sequentially ordered and related by simple links. They like to use a simple step-by-step strategy and consequently regard embellishments such as anecdote, illustration and analogy as quite distracting. Holists, on the other hand, prefer a more global approach to problem-solving. They use more complex non-linear 'globetrotting' strategies, and thrive on anecdote, illustration and analogy. By focusing on a 'global' approach, they concentrate on synthesizing broad overviews into which details may be fitted. By contrast, serialists use more of a 'local' approach, concentrating on specifics which may then lead to the emergence of an overall picture. Individuals able to function happily either way are referred to as 'versatile'. Entwistle $(1978,1981)$ summarizes the research associated with this serialist/holist style.

\section{Application of the serialist/holist style to CAL}

Identifying an appropriate style is only the first step. What is also required is a quick and reliable measure of that style which can be incorporated into a CAL program. The original identification procedures used by Pask (1973) are pencil-and-paper tests, and are quite lengthy and complex. Building on Pask's work, Entwistle (1981) developed a more efficient 30-item Short Inventory of Approaches to Studying. In turn, Ford (1985) has developed an 18-item questionnaire, Study Preference Questionnaire (SPQ) but unfortunately provides no information on its reliability. A copy of the questionnaire is given in the Appendix.

The requirement here is a quick and reliable measure of style. Ford found that using a small English sample of 25 postgraduate students, one of the items (Question 16) in the SPQ significantly predicted serialist or holist tendencies at $\mathrm{p}<0.01$ level. The item is: 
When I'm reading a book (or other information source) for my studies, I prefer to work through it fairly logically from beginning to end.
When I'm reading a book (or other information source) for my studies, I prefer to skip about and and 'dip in' quite a lot.

(See the last page of the Appendix for the interpretation of the response scale.)

If a similar finding, derived from a reliable questionnaire can be produced using a sample for whom CAL programs are to be produced - Australian in this case - it would provide a simple method of indicating the CAL user's cognitive style, and it could be very simply incorporated into any CAL program.

\section{An Australian replication of the Ford study}

The ultimate aim of the project in which I am currently engaged (Clarke, in process) is to produce CAL materials for teacher-education students in educational psychology. Hence, any replication of Ford's work needs to involve such students. The SPQ was administered to 56 students involved in a one-year postgraduate pre-service teacher-education course at a large teacher-education institution in Brisbane. All students had completed an undergraduate qualification at a different tertiary institution.

The responses were analysed with the aims of producing a reliable questionnaire and of determining if responses to any individual question were significantly correlated with responses to the full questionnaire. The data was analysed using modules of the statistical package SYSTAT (Wilkinson, 1988) and the results are reported below. ${ }^{2}$

\section{Results}

The reliability of the 18-item questionnaire was estimated by using the coefficient alpha procedure (Cronbach, 1951). Then, the correlation of each item with the alpha value, and simultaneously the effect on alpha of removing individual items from the calculations, were measured. If the value of alpha increases with the removal of an item, it is possible to conclude that the item is not measuring the same characteristics as the total test and in fact is interfering with obtaining a 'pure' measure of those characteristics. This process of removing items therefore increases the reliability of the test. It is continued until alpha is not increased by any further removal of items. Five items were removed using this procedure. The results are summarized in Table 1.

The outcome of this analysis is the identification of a 13-item test which is much more reliable than the original 18-item measure. The alpha value increased from 0.594 to 0.670 which is significant at the 0.01 level. 


\begin{tabular}{|c|c|c|c|c|}
\hline Coefficient Alpha & Item No. & $\begin{array}{l}\text { Coefficient Alpha } \\
\text { if item exluded }\end{array}$ & $\begin{array}{l}\text { Item } \\
\text { number }\end{array}$ & $\begin{array}{l}\text { Item-alpha } \\
\text { correlation }\end{array}$ \\
\hline 0.594 & 2 & 0.635 & \multirow[b]{2}{*}{1} & \\
\hline 0.635 & 12 & 0.657 & & 0.418 \\
\hline 0.657 & 9 & 0.688 & 3 & 0.416 \\
\hline 0.668 & 11 & 0.669 & 4 & 0.359 \\
\hline 0.669 & 8 & 0.670 & 5 & 0.595 \\
\hline 0.670 & \multirow{2}{*}{\multicolumn{2}{|c|}{ No item with alpha $>0.670$}} & & 0.423 \\
\hline & & & $\Omega$ & 0.628 \\
\hline \multirow{6}{*}{\multicolumn{3}{|c|}{ Table 1: Summary of the item elimination procedure }} & 10 & 0.404 \\
\hline & & & 13 & 0.428 \\
\hline & & & 14 & 0.446 \\
\hline & & & 15 & 0.412 \\
\hline & & & 16 & 0.427 \\
\hline & & & 17 & 0.509 \\
\hline \multicolumn{3}{|c|}{$\begin{array}{l}\text { Table 2: Individual item-total } \\
\text { measure correlations }\end{array}$} & 18 & 0.356 \\
\hline
\end{tabular}

The ultimate aim here is to identify an individual item that can be used instead of the total (now reduced) questionnaire. The correlations between each of the remaining 13 items and the coefficient alpha are shown in Table 2.

Question 7 has the highest correlation and hence could possibly be used to identify those students with serialist or holist tendencies. The item is as follows:

7. When I'm reading a book (or other information source) for my studies, I prefer to spend quite a long time skimming over and dipping into it to get a clear picture of what it's about and how it will be relevant.
When I'm reading a book (or other information source) for my studies, I prefer to get quite soon into $\begin{array}{lllll}1 & 2 & 3 & 4 & 5\end{array}$ a fairly detailed reading of it once I know that it's going to be useful, in the knowledge that its precise relevance and contribution will become clear from a detailed reading 
It is outside of the scope of this paper to speculate why Question 16 did not emerge as the most important item as in the Ford study. ${ }^{3}$ There are, however, a number of ways in which this data could be used to help cater for the different cognitive styles of CAL users (Clarke, 1990). One method is to incorporate Question 7 into the CAL program.

Incorporation of Question 7 into a CAL program

Since only one question is involved, it is a simple procedure to place it at the beginning of a CAL package and use the response to direct users to the appropriate tutorial-type or

\section{Welcome to the School of Learning and Development's Computer Based Learning Series of Programs PROGRAM 1 - How Students Learn}

There are two different versions of this program available. The computer will allocate you to Version $A$ or Version $B$ according to your response to this question:

When I'm reading a book (or other information source) for my studies, I prefer to spend quite a long time skimming over and dipping into it to get a clear picture of what it's about and how it will be relevant.
When I'm reading a book (or other information source) for my studies, I prefer to get quite soon into a fairly detailed reading of it once I know it's going to be useful, in the knowledge that its precise relevance and contribution will become clear from a detailed reading.

$1=$ I agree with the statement on the left

$2=1$ agree (with reservations) with the statement on the left

$3=$ No preference for either statement

$4=$ I agree (with reservations) with the statement on the right

$5=1$ agree with the statement on the right

Please place a response $(1,2,3,4$ or 5$)$ in the space below:

YOUR RESPONSE

Figure 1: Procedure which could appear at the beginning of a CAL lesson 
simulation-type version of the program. An appropriate procedure could be as shown in Figure 1. This could appear as a frame at the beginning of a CAL lesson.

Those who choose 1 or 2 will be allocated to Version $B$; those who choose 4 or 5 will be allocated to Version A; those who choose 3 will be told that it doesn't really matter which version they use, and will be given the option of choosing version $A$ or or version $B$.

\section{The next steps}

There are at least two things that now need to be done. First, the preparation of a suite of CAL programs where each program is available in two versions - tutorial and simulation; and secondly a measure of the predictive validity of Question 7. Work is proceeding on the former (Clarke, in process). Two versions of a program designed to introduce pre-service teacher education students to 'How Children Learn' are being developed. Once these are available, work can proceed on the latter.

The second issue, that of predictive validity, can be addressed in several ways. One approach would be to gather data from users on the appropriateness or otherwise of the allocation made as a result of their response to Question 7 and their satisfaction with the type of learning experience they subsequently have. Another approach would be to investigate the relative reliability of an allocation based on one question, compared to an allocation based on a small group of questions or an allocation based on simple user choice premised on information about the two versions.

\section{Notes}

1. An earlier version of this paper was presented at the Seventh Annual Conference of the Australian Society for Computers in Leaming in Tertiary Education, Bond University, Gold Coast, Queensland, Australia, 10-13 December, 1989.

2. The assistance of Dr D. Chant, Statistical Adviser to the Social Sciences, University of Queensland, in this analysis is gratefully acknowledged.

3. One likely explanation is the potentially interfering effects of those items removed in the reliability analysis reported here. Other explanations could relate to differences in the size and characteristics of the samples. 


\section{References}

Barker, P.G. (1982), 'Some experiments in man-machine interaction relevant to computerassisted instruction', British Journal of Educational Technology, 13, 1, 65-75.

Chadwick, S.S. and Watson, J.A. (1986), 'Computers and cognitive styles', Academic Therapy, 22, 2, 125-32.

Clarke, J.A. (1990), 'Designing CAL programs to cater for different learning styles', in McDougall, A. and Dowling, C. (eds), Computers in Education, Amsterdam, Elsevier Science Publishers, 351-8.

Clarke, J.A. (in process), 'The production of a Computer-Assisted Learning (CAL) package for tertiary students that is designed to cater for the preferred learning styles of students', Report of a Professional Experience Program (PEP) being undertaken at the CAL Unit, University of Queensland.

Clements, D.H. and Gullo, D.F. (1984), 'Effects of computer programming on young children's cognition', Journal of Educational Psychology, 76, 6, 1051-8.

Coop, R.H. and Sigel, I. (1971), 'Cognitive style: Implications for learning and instruction', Psychology in the Schools, 8, 152-61.

Cronbach, L.J. (1951), 'Coefficient alpha and the internal structure of tests', Psychometrica, 35, 509-11.

Dahl, R.D. (1985), 'Interaction of field dependence-independence with computer assisted instruction structure in an orthographic projection lesson', unpublished doctoral dissertation, Iowa State University, Dissertation Abstracts International, 45, $2012 \mathrm{~A}$.

Duncan, M.V. (1985), 'Computer programs and learning styles', Computers, Reading and Language Arts, 2, 2, 8-12.

Entwistle, N. (1978), 'Knowledge structures and styles of learning: a summary of Pask's recent research', British Journal of Educational Psychology, 48, 225-65.

Entwistle, N. (1981), Styles of Learning and Teaching, New York, John Wiley.

Ford, N. (1985), 'Learning styles and strategies of postgraduate students', British Journal of Educational Technology, 16, 1, 17-26.

James, J.S. and James, L.L. (1990), 'Learning styles and computer programming activities', in McDougall, A. and Dowling, C. (eds), Computers in Education, Amsterdam, Elsevier Science Publishers, 397-402.

Jougnin, G. (1989), 'Adult learning principles and field-dependence/independence in training program design', paper presented at the Australia and South Pacific External Studies Association Ninth Biennial Forum, Gippsland Institute of Advanced Education.

Kogan, N. (1971), 'Educational implications of cognitive styles', in Lesser, G.S. (ed), Psychology and Educational Practice, Illinois, Scott Foresman, 242-92. 
Messick, S. (1970), 'The criterion problem in the evaluation of instruction: assessing possible, not just intended outcomes', in Wittrock, M.C. and Wiley, D.E. (eds), The Evaluation of Instruction: Issues and Problems, New York, Holt Rinehart and Winston, 183-202.

Messick, S. (1976) 'Personality consistency in cognition and creativity' in Messick, S. (ed), Individuality in Learning, San Francisco, Jossey-Bass, 4-22.

Messick, S. (1984), 'The nature of cognitive style: problems and promises in educational practice', Educational Psychologist, 19, 2, 59-74.

Pask, G. (1973) Educational Methods using Information about Individual Styles and Strategies of Learning, final report of the SSRC Project HR 1424/1 (2 volumes).

Pask, G. (1976), 'Styles and strategies of learning', British Journal : of Educational Psychology, 46, 128-48.

Pask, G. and Scott, B.C.E. (1972), 'Learning strategies and individual competence', International Journal of Man-Machine Studies, 4, 217-53.

Post, P.E. (1985), 'The effect of students' field independence/dependence on computerassisted instruction achievement', unpublished doctoral dissertation, Purdue University, Dissertation Abstracts International, 45, 2013A-2014A.

Rowland, P. and Stuessy, C.L. (1987), 'Effects of modes of computer-assisted instruction on conceptual understanding and achievement of College students exhibiting individual differences in learning: a pilot study', paper presented at the annual meeting of the National Association of Research in Science Teaching, Washington DC. ,

Sims, R. (1988), 'Towards learner-centred computer-assisted learning' in Fielden, K., Hicks, F. and Scott, N. (eds), Computers in Learning in Tertiary Education, Canberra, ASCILITE.

Sharma, S. (1987), 'Learners' cognitive styles and psychological types as intervening variables influencing performance in computer science courses', Journal of Educational Technology Systems, 15, 4, 391-9.

Wesley, B.E. (1984), 'The effect of computer-assisted instruction and locus of control upon preservice elementary teachers' acquisition of computer literacy and the integrated process skills', unpublished doctoral dissertation, Purdue University, Dissertation Abstracts International, 44, 3652A.

Wilkinson, L. (1988), SYSTAT: The System for Statistics, Evanston, IL, SYSTAT Inc.

Witkin, H.A., Dyk, R.B., Faterson, H.F., Goodenough, D.R. and Karp, S.A. (1962), Psychological Differentiation: Studies of Development, New York, John Wiley.

Witkin, H.A., Oltman, P.K., Raskin, E. and Karp, S.A. (1971), A Manual for the Embedded Figures Test, Consulting Psychologists Press. 


\section{Appendix}

\section{Study preference questionnaire}

1. When I'm reading a book (or other information source) for my studies, I generally tend to concentrate on certain parts, and skip over others quite markedly, going back later if necessary to fill in any 'gaps' or 'missing links'.

2. When I'm studying for an essay, I try to gather as much information as possible at the start.

3. When I'm studying I generally prefer to deal reasonably thoroughly with one book (or other information source) before moving on to another.

4. When I'm studying a new subject, I tend to want to keep the whole picture of the subject in my mind all the time and find it hard to concentrate on very detailed aspects unless I can constantly relate them clearly to the broad overall picture.

5. When I'm in the library, generally speaking I tend to be looking for specific books, etc. rather than browsing.
When I'm reading a book (or other information source) for my studies, I tend to follow $\begin{array}{lllll}1 & 2 & 3 & 4 & 5\end{array}$ the author's presentation reasonably closely, rather than skipping about a lot.

I prefer to have more of a

$\begin{array}{llll}1 & 2 & 3 & 4\end{array}$

4

5 'steady flow' throughout my preparation for the essay.

I generally prefer to have a number of books (or other

$\begin{array}{llll}1 & 2 & 3 & 4\end{array}$

5 information sources) 'on the go' at the same time.

Once I've analysed the subject into its component parts,

$\begin{array}{llll}2 & 2 & 4 & 4\end{array}$ I like to focus on each of these parts in detail, systematically building up the overall picture bit by bit.

$12 \quad 3 \quad 4$

I tend to spend quite a lot of time browsing in the library. 
6. For students who learn in the way I do, the best form of training in library use would be to follow a well structured course, building up from the basics and going on to more complex skills that will be essential for them to know.

7. When I'm reading a book (or other information source) for my studies, I prefer to spend quite a long time skimming over and dipping into it to get a clear picture of what it's about and how it will be relevant.

8. Generally I prefer to concentrate on one (or a very few) aspect(s) of a subject at a time when I'm learning about it.

9. Once I've done a basic analysis of what the subject involves, I'm happy to put to the back of my mind temporarily the broad overall picture while I do some work on more detailed aspects.

10. Summaries of a wide range of books (and other information sources) would not really be much use to me when I'm doing an essay - I really need the full texts more or less straight away.
For students who learn in the way I do, the best form of training in library use would $\begin{array}{llll}1 & 2 & 3 & 4\end{array}$

$\begin{array}{llll}1 & 2 & 3 & 4\end{array}$

Generally I prefer to be $\begin{array}{llll}1 & 2 & 3 & 4\end{array}$ 5 learning about a number of different aspects of a subject at the same time.

I tend to want to keep the overall picture uppermost in my mind the whole time, and $\begin{array}{lllll}1 & 2 & 3 & 4 & 5\end{array}$ only work on more detailed aspects if I can see precisely how they will fit into this picture.

Summaries would be very $\begin{array}{llll}1 & 2 & 3 & 4\end{array}$ 5 useful in the initial stages of my work on an essay. 
11. I like to approach a new subject in a broad way often looking at widely spaced aspects of the subject and seeing how they may all fit together, before going back to 'fill in' any strictly logical steps that I have skipped.

12. When I'm doing an essay, I think that $I$ tend to use rather fewer information sources than most students on the course.

13. I find it too restrictive to wait until I have thoroughly 'mastered' one aspect of a new subject I am learning about before going on to study other aspects.

14. Where a book chapter or journal article includes a separate summary of what it is about, I generally prefer to get straight into the main text since it contains all that is in the summary anyway.

15. When I'm studying for an essay, I like to start by 'soaking in' a wide range of information in order to get the 'feel' of the subject

16. When I'm reading a book (or other information source) for my studies, I prefer to work through it fairly logically from beginning to end.
I like the logical links between different aspects of a new subject to be very close,

$\begin{array}{llll}1 & 2 & 3 & 4\end{array}$

$\begin{array}{llll}1 & 2 & 3 & 4\end{array}$

$\begin{array}{llll}1 & 2 & 3 & 4\end{array}$

$\begin{array}{llll}1 & 2 & 3 & 4\end{array}$

$\begin{array}{llll}1 & 2 & 3 & 4\end{array}$ $\begin{array}{llll}1 & 2 & 3 & 4\end{array}$
I like to deal fairly thoroughly with the particu5 lar aspect I'm working on before going on to study others.

Generally I prefer to read the summary before reading the 5 full text - even though it will all be found in greater detail in the main text.
I prefer to analyse the topic 5 fairly early on, and search for information which is more clearly focused on particular aspects of the topic.

When I'm reading a a book 5 (or other information source) for my studies, I prefer to skip about and 'dip in' quite a lot. 
17. Where a book or journal has a separate summary of conclusions I prefer to get straight into the main text, where each conclusion is presented along with the evidence on which it is based.
18. When I'm learning about a new subject, I like to keep coming back to particular aspects on different occasions, to get further details as I require them.
I prefer to spend quite a bit of time reading the summary $\begin{array}{llllll}1 & 2 & 3 & 4 & 5 & \text { of conclusions before going }\end{array}$ on to a detailed reading of the main text.

I prefer to deal with particular aspects of a new subject 5 as thoroughly as I can at one time, so that I need not keep returning to them on different occasions to get further details.

\section{Response scale}

$1=I$ agree with the statement on the left

$2=$ I agree (with reservations) with the statement on the left

$3=$ No preference for either statement

$4=\mathrm{I}$ agree (with reservations) with the statement on the right

$5=I$ agree with the statement on the right 